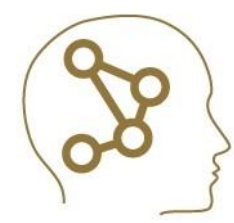

\title{
Investigation with Structural Equation Model of the Relationship between Covid-19 Phobia and Secondary Traumatic Stress Level in 112 Emergency Service Personnel
}

\author{
${ }^{1}$ Serdar Derya ${ }^{\mathbb{D},}{ }^{2}$ Bora Tetik ${ }^{(\mathbb{D} \text {, and }}{ }^{3}$ Leman Acun Delen $(\mathbb{D}$ \\ ${ }^{1}$ Malatya Training and Research Hospital, Department of Traumatology and Emergency Medicine, Malatya, Turkey. (e-mail: dr.serdarderya@gmail.com). \\ ${ }^{2}$ Inonu University School of Medicine, Deparment of Neurosurgery, Malatya, Turkey. (e-mail: drboratetik@hotmail.com) \\ ${ }^{3}$ Malatya Training and Research Hospital, Department of Anesthesiology and Reanimation, Malatya, Turkey. (e-mail: 1mndelen@ @otmail.com)
}

\section{ARTICLE INFO}

Received: Feb.,22.2021

Revised: March.,23.2021

Accepted: May.,27.2021

Keywords:

112 emergency service personnel

Covid-19 phobia

Secondary traumatic stress level

Structural equation mode

Corresponding author: Bora Tetik

$\triangle$ drboratetik@hotmail.com

용 +905056212427

ISSN: $2548-0650$

\begin{abstract}
The impact of the Covid-19 pandemic on healthcare workers is increasing day by day. It should not be forgotten that health professionals working in risky groups will be psychologically affected much more. The aim of this cross-sectional study is determine the relationship between covid-19 phobia and secondary traumatic stress level in 112 emergency service personnel via a structural equation model $(n=416)$.A 1 -unit change that was occur in the total score of the trauma scale causes an increase of 0.68 units in the phobia scale total score $(\beta=0.68 ; p<0.001)$.In addition, it was determined that female personnel, those with a history of contact with a covid-19 positive colleague, and those who stated to be extremely worried about the possibility of a second wave, had a high level of phobia and STS levels. In addition to all risks, it should not be forgotten that 112 personnel exposed to psychologically affected in combating pandemic should be supported separately.
\end{abstract}

DOI: https://doi.org/10.52876/jcs.912227

\section{INTRODUCTION}

$\mathrm{T}$ HE struggle against the pandemic continues actively in our country, since March 11, 2020, when COVID 19 has been announced to be a pandemic by WHO. It was the same day the first case was reported, in our country. It is still unclear how long this process will continue, when the vaccine will be available and when global immunity will occur. Unavailability of a definitive cure, when a second wave of spread has been experienced in some countries, while the first wave is continuing in some countries, including Turkey, significantly increases the anxiety of people. As of September 2020 the number of patients diagnosed with COVID-19 was 29.125.191 in the world and 291.162 in Turkey [1].

Continuous publications in the press and the media, social distancing, shot down of schools and some workplaces within the scope of preventing the transmission of the disease, people's feelings of being imprisoned at home, and most importantly, the uncertainty of this period will probably have additional psychological effects on the healthcare professionals, who are working in a more risky environment. It is known that psychological stress makes people vulnerable to acute respiratory infections, and stress causes activation of the hypothalamus-hypophyse axis and autonomic nervous system [2,3]. The effects of COVID 19 pandemic on healthcare workers has been increasing day by day. The emotional state experienced by individuals as a result of witnessing a tragic event or being indirectly exposed to it because of their job is called secondary traumatic stress, and healthcare personnel are at risk in terms of secondary traumatic stress during the covid-19 process [4]. Furthermore, it is predicted that, those working in 112 Emergency Service, which is the most risky group, will more frequently be affected psychologically.

Both the increase in the number of patients and the increasing rate of positive cases, even deaths among 
healthcare personnel make the situation more complicated. 112 emergency service personnel are in one of the most risky groups, in this process. In this study, we planned to investigate the psychological effects of the COVID-19 epidemic on 112 employees, prevalence of these effects, and the relationship between sociodemographic variables and the rate of taking precautions. To the best of our knowledge, this is the first study investigating the psychological effects of pandemic on 122 employees. We believe that the data we present will be guiding for both public health services and health-care administrators.

\section{MATERIALS AND METHODS}

\subsection{Dataset}

The aim of this cross-sectional study is determine the relationship between covid-19 phobia and secondary traumatic stress level in 112 emergency service personnel via a structural equation model.

\subsection{Setting and Time of the Study}

This study was conducted on 112 Emergency Service employees, working in a province located in the east of Turkey, between July 2020 and August 2020.

\subsection{The Universe and Sample of the Research}

The universe of the study was composed of all 112 emergency service personnel (ATT, Paramedic, Ambulance Driver, Doctor) serving within the relevant "Provincial Ambulance Service Chief Physician". The personnel working within the Provincial Ambulance Service Head Physician include 212 ATTs, 168 Paramedics, 45 Ambulance Drivers and 22 Doctors (total $=447$ ). In the power analysis in order to achieve 5\% error level, $95 \%$ confidence interval and the ability to represent the $80 \%$ of the universe, it has been calculated found the sample size should be at least 207 personnel. The study was conducted on with 416 Emergency Service personnel who voluntarily agreed to participate in the study.

\subsection{Data Collection Tools}

Personal Information Form, Coronavirus 19 Phobia Scale (C19P-S), and Secondary Traumatic Stress Scale (STSS) were applied to the participants.

Personal Introduction Form; This form consists of 12 questions that question the sociodemographic characteristics (age, gender, education level, etc.) of the participants and their experiences during the Covid-19 pandemic process.

Coronavirus 19 Phobia Scale (C19P-S); C19P-S is a 5grade Likert-type self-assessment scale developed by Arpaci et al. (2020), to measure the phobia of corona virus. The questions were answered on a 5 grade scale where 1 represents "Strongly Disagree" and 5 "Strongly Agree". It is consisted of 20 questions divided into 4 sub dimensions. Psychological Sub-Dimension includes the questions 1, 5, 9, 13, 17, and 20; Somatic Sub-Dimension includes the questions 2, 6, 10, 14, and 18; Social Sub-Dimension includes the questions 3, 7, 11, 15, and 19; and Economic Sub-Dimension includes questions $4,8,12$, and 16. Sub-dimension scores are obtained by the sum of the scores of the answers given to the questions under that sub-dimension, the total C19P-S score is obtained by the sum of the sub-dimension scores. The total score from the
C19P-S varies between 20 and 100. The higher of the scores indicate the higher level of corona phobia. The cronbach alpha value of the scale was determined to be 0.92 [5]. In this study, the cronbach alpha value was found as 0.95 .

Secondary Traumatic Stress Scale (STSS); STSS was developed by Bride et al. and Turkish adaptation was conducted by Yildirim et al., in 2018. It is a 17-item, fivepoint Likert-type assessment tool. The scale has three subdimensions including involuntary involvement, avoidance, and arousal. The lowest score that can be obtained from the scale is 17 and the highest score is 85 . A higher score indicates a higher level of exposure. The cronbach alpha value of the scale was determined to be 0.91 , by Yildirim et al. [6]. In this study, the cronbach alpha value was found as 0.94 .

\subsection{Data Collection}

Data collection forms were sent to 112 emergency service personnel, who agreed to participate in the study, via the telephone network and internet using the Google form method, and the forms were requested to be filled by the participants. At the beginning, the personnel who accepted to participate in the study were asked to approve the informed consent form by using the Google form method. All data were obtained by online self-report method and recorded by using Google form method. The data collection phase took about 58 minutes for each participant.

\subsection{Evaluation of Data}

The data were evaluated by using the AMOS 24 and SPSS 25.0 statistical package program. The descriptive statistics were presented as number, percentage, mean, standard deviation, min-max. In addition, in independent groups $t$ test, ANOVA test, Pearson correlation analysis and structural equation model were used. Results were evaluated at $95 \%$ confidence interval and a value of $p<0.05$ was considered statistically significant.

\subsection{Ethical Approval}

An institutional permission from the relevant Provincial Ambulance Service Chief Physician and ethical approval from the Inonu University Health Sciences Scientific Research and Publication Ethics Committee were obtained before the study was started (Decision No: 2020/953). In addition, permission of Republic of Turkey Ministry of Health Covid-19 for Scientific Research was obtained (Form Number: 2020-0628T22_47_30). Informed Consent Forms were also obtained from the participants after the necessary explanations were made and before they filled the data collection forms.

\section{RESULTS}

The mean age of the participants is $29.54 \pm 7.95 ; 51.2 \%$ are women; $54.5 \%$ are associate degree graduates; $52.9 \%$ are married; $89.4 \%$ are working as ATT / Paramedic; and $86.3 \%$ of them are working 112 stations. Sociodemographic characteristics of the 112 emergency service personnel and comparison of C19P-S and STSS scale scores are given in Table 1.

It was determined that Covid-19 Phobia and Secondary Traumatic Stress scores of female 112 emergency service personnel were statistically significantly higher than the male personnel $(\mathrm{p}<0.05)$. It was also determined that the personnel 
working as ATT / paramedic had significantly higher C19P-S and STSS scores compared to the drivers $(\mathrm{p}<0.05)$.

TABLE 1

COMPARISON OF C19P-S AND STSS SCORES ACCORDING TO THE DESCRIPTIVE FEATURES OF 112 EMERGENCY SERVICES PERSONNEL

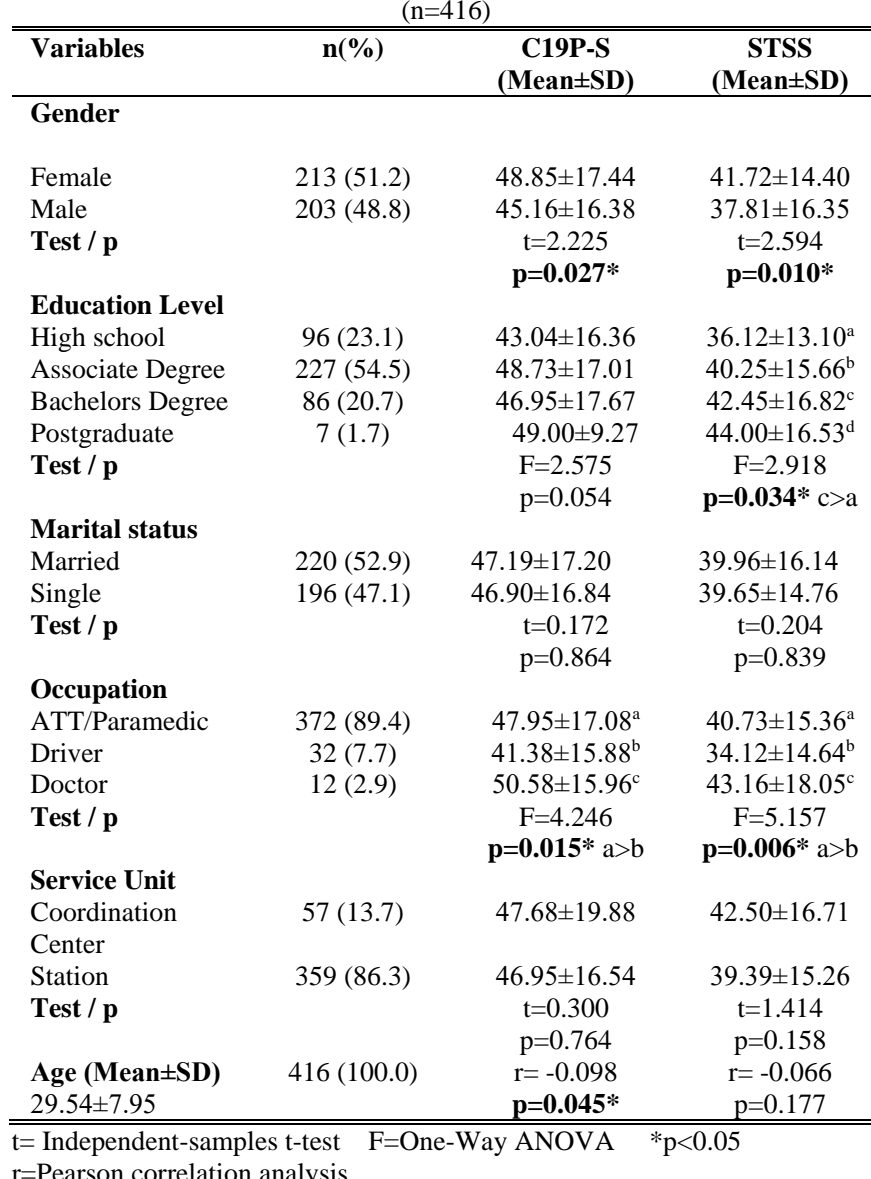

In addition, it was found that STSS scores increased as the level of education advanced; 112 emergency service personnel with a bachelor's degree had higher STSS scores than high school graduates ( $\mathrm{p}<0.05)$. On the other hand, it was determined that $\mathrm{C} 19 \mathrm{P}-\mathrm{S}$ scores decreased significantly as age increased in all 112 emergency service personnel $(p<0.05)$ (Table 1)

Table 2 shows the distribution of 112 emergency service personnel according to Covid-19 experiences and the comparison of Covid-19 phobia and secondary traumatic stress levels according to these experiences. We found that $86.1 \%$ of the 112 emergency service personnel had transferred Covid-19 patients, $20.4 \%$ had a history of a contact with a Covid-19 positive patient, and $23.1 \%$ had a history of a contact with a Covid-19 positive colleague. The rate of those diagnosed with Covid-19, among 112 emergency service personnel is found to be $7.5 \%$. In addition, $54.3 \%$ of the 112 emergency service personnel stated that they stayed in a guest house or a different house to protect their family members, and $37.3 \%$ stated that they were anxious about the possibility of a second wave (Table 2).

We found that 112 emergency service personnel with a history of contact with a Covid-19 positive colleague had higher C19P-S and STSS scores compared to those without a contact history.
TABLE 2

COMPARISON OF C19P-S AND STSS SCORES ACCORDING TO THE COVID-19 EXPERIENCES OF 112 EMERGENCY SERVICE PERSONNEL $(n=416)$

\begin{tabular}{|c|c|c|c|}
\hline Variables & $\mathrm{n}(\%)$ & $\begin{array}{c}\text { C19P-S } \\
(\text { Mean } \pm \text { SD })\end{array}$ & $\begin{array}{c}\text { STSS } \\
(\text { Mean } \pm \text { SD }) \\
\end{array}$ \\
\hline \multicolumn{4}{|l|}{$\begin{array}{l}\text { Have you ever } \\
\text { transferred Covid-19 } \\
\text { patients? }\end{array}$} \\
\hline Yes & $358(86.1)$ & $46.38 \pm 16.62$ & $39.28 \pm 15.30$ \\
\hline No & $58(13.9)$ & $51.18 \pm 18.89$ & $43.12 \pm 16.33$ \\
\hline Test / p & & $\begin{array}{l}\mathrm{t}=-2.002 \\
\mathbf{p}=\mathbf{0 . 0 4 6 *}\end{array}$ & $\begin{array}{c}\mathrm{t}=-1.755 \\
\mathrm{p}=0.080\end{array}$ \\
\hline \multicolumn{4}{|l|}{$\begin{array}{l}\text { Have you ever been in } \\
\text { contact with a Covid-19 } \\
\text { positive patient? }\end{array}$} \\
\hline Yes & $85(20.4)$ & $48.94 \pm 19.53$ & $42.42 \pm 17.95$ \\
\hline No & $331(79.6)$ & $46.57 \pm 16.30$ & $39.14 \pm 14.74$ \\
\hline Test / p & & $\begin{array}{l}\mathrm{t}=1.146 \\
\mathrm{p}=0.252\end{array}$ & $\begin{array}{l}\mathrm{t}=1.743 \\
\mathrm{p}=0.082\end{array}$ \\
\hline \multicolumn{4}{|l|}{$\begin{array}{l}\text { Have you ever been in } \\
\text { contact with a Covid-19 } \\
\text { positive colleague? }\end{array}$} \\
\hline Yes & $96(23.1)$ & $50.17 \pm 18.45$ & $45.23 \pm 16.07$ \\
\hline No & $320(76.9)$ & $46.11 \pm 16.47$ & $38.19 \pm 14.95$ \\
\hline Test / p & & $\begin{array}{c}\mathrm{t}=2.058 \\
\mathbf{p}=\mathbf{0 . 0 4 0} *\end{array}$ & $\begin{array}{c}t=3.980 \\
\mathbf{p}=\mathbf{0 . 0 0 0} *\end{array}$ \\
\hline \multicolumn{4}{|l|}{$\begin{array}{l}\text { Have you been } \\
\text { diagnosed with Covid- } \\
19 \text { ? }\end{array}$} \\
\hline Yes & $31(7.5)$ & $44.61 \pm 17.49$ & $41.51 \pm 13.69$ \\
\hline No & $385(92.5)$ & $47.25 \pm 16.98$ & $39.68 \pm 15.63$ \\
\hline Test / p & & $\begin{array}{l}\mathrm{t}=-0.830 \\
\mathrm{p}=0.407\end{array}$ & $\begin{array}{l}t=0.634 \\
p=0.526\end{array}$ \\
\hline \multicolumn{4}{|l|}{$\begin{array}{l}\text { Measures taken to } \\
\text { protect family } \\
\text { members }\end{array}$} \\
\hline $\begin{array}{l}\text { Staying in a guest house } \\
\text { or a different home }\end{array}$ & $226(54.3)$ & $47.96 \pm 17.68$ & $40.12 \pm 16.16$ \\
\hline $\begin{array}{l}\text { Implementing social } \\
\text { isolation / cleaning } \\
\text { measures at home }\end{array}$ & $190(45.7)$ & $45.97 \pm 16.16$ & $39.45 \pm 14.68$ \\
\hline Test / p & & $\begin{array}{l}\mathrm{t}=1.189 \\
\mathrm{p}=0.235\end{array}$ & $\begin{array}{l}\mathrm{t}=0.440 \\
\mathrm{p}=0.660\end{array}$ \\
\hline \multicolumn{4}{|l|}{$\begin{array}{l}\text { Level of anxious about } \\
\text { the probability of a } \\
\text { second wave }\end{array}$} \\
\hline Not at all & $35(8.4)$ & $34.51 \pm 11.89^{\mathrm{a}}$ & $32.14 \pm 15.36^{\mathrm{a}}$ \\
\hline Partially anxious & $94(22.6)$ & $39.41 \pm 12.28^{b}$ & $33.53 \pm 11.36^{\mathrm{b}}$ \\
\hline Anxious & $155(37.3)$ & $46.15 \pm 12.46^{\mathrm{c}}$ & $36.40 \pm 11.28^{\mathrm{c}}$ \\
\hline Very anxious & $132(31.7)$ & $56.87 \pm 20.21^{\mathrm{d}}$ & $50.34 \pm 16.97^{d}$ \\
\hline Test / p & & $\begin{array}{c}\mathrm{F}=34.020 \\
\mathbf{p}=\mathbf{0 . 0 0 0} * \\
\mathrm{~d}>\mathrm{a}, \mathrm{b}, \mathrm{c} \\
\mathrm{c}>\mathrm{a}, \mathrm{b}\end{array}$ & $\begin{array}{c}\mathrm{F}=39.408 \\
\mathbf{p}=\mathbf{0 . 0 0 0 *} \\
\mathrm{d}>\mathrm{a}, \mathrm{b}, \mathrm{c}\end{array}$ \\
\hline
\end{tabular}

In addition, 112 emergency service personnel who stated that they were "very worried" against the possibility of a second wave were found to have the highest C19P-S and STSS scores compared to other anxiety levels $(\mathrm{p}<0.05)$.

We also found that C19P-S scores of the 112 emergency service personnel who did not transfer Covid-19 patients were statistically significantly higher than those who had transferred Covid-19 patients ( $\mathrm{p}<0.05)$ (Table 2).

It was determined that the mean total C19P-S score of the 112 Emergency Service personnel was $47.05 \pm 17.01$, and the mean total STSS score was $39.81 \pm 15.49$. according to the results of the Pearson's correlation analysis, it was determined that there was a moderately significant positive correlation between the mean total C19P-S and STSS scores, and as STSS scores increased Covid-19 phobia increased significantly, in 112 emergency service personnel ( $p<0.001)$. In addition, it was found that there was a positive significant relationship 
between the mean total and all sub-dimension scores of STSS and C19P-S ( $\mathrm{p}$ <0.001). Data showing the relationship between covid-19 phobia and secondary traumatic stress levels in 112 emergency service personnel is shown in Table 3.

TABLE 3

THE RELATIONSHIP BETWEEN COVOD-19 PHOBIA (C19P-S) AND SECONDARY TRAUMATIC STRESS LEVELS (STSS) IN 112 EMERGENCY SERVICE PERSONNEL

\begin{tabular}{|c|c|c|c|c|}
\hline \multirow[b]{2}{*}{$\begin{array}{l}\text { C19P-S } \\
(\text { mean } \pm \text { SD) }\end{array}$} & \multicolumn{4}{|c|}{ STSS $($ mean \pm SD) } \\
\hline & $\begin{array}{l}\text { Involuntary } \\
\text { involvement } \\
(10.62 \pm 4.40)\end{array}$ & $\begin{array}{c}\text { Avoidance } \\
(17.00 \pm 6.52)\end{array}$ & $\begin{array}{c}\text { Alertness } \\
(12.19 \pm 5.56)\end{array}$ & $\begin{array}{c}\text { Total } \\
(39.81 \pm 15.49)\end{array}$ \\
\hline Psychological & $r=0.382$ & $\mathrm{r}=0.520$ & $r=0.544$ & $r=0.523$ \\
\hline$(16.55 \pm 6.55)$ & $\mathrm{p}=0.000 *$ & $\mathbf{p}=0.000 *$ & $\mathbf{p}=0.000 *$ & $\mathbf{p}=0.000 *$ \\
\hline Somatic & $\mathrm{r}=0.478$ & $\mathrm{r}=0.534$ & $\mathrm{r}=0.558$ & $r=0.562$ \\
\hline$(9.78 \pm 4.04)$ & $\mathrm{p}=0.000 *$ & $\mathrm{p}=0.000^{*}$ & $\mathrm{p}=0.000 *$ & $\mathrm{p}=0.000^{*}$ \\
\hline Social & $\mathrm{r}=0.417$ & $\mathrm{r}=0.568$ & $\mathrm{r}=0.568$ & $\mathrm{r}=0.562$ \\
\hline$(12.72 \pm 5.15)$ & $\mathbf{p}=0.000 *$ & $\mathrm{p}=0.000 *$ & $\mathbf{p}=0.000 *$ & $\mathbf{p}=0.000 *$ \\
\hline Economic & $\mathrm{r}=0.381$ & $\mathrm{r}=0.453$ & $\mathrm{r}=0.464$ & $\mathrm{r}=0.466$ \\
\hline$(7.99 \pm 3.31)$ & $\mathbf{p}=0.000 *$ & $\mathrm{p}=0.000 *$ & $\mathrm{p}=0.000 *$ & $\mathbf{p}=0.000 *$ \\
\hline Total & $\mathrm{r}=0.461$ & $\mathrm{r}=0.588$ & $r=0.604$ & $\mathrm{r}=0.596$ \\
\hline$(47.05 \pm 17.01)$ & $\mathrm{p}=0.000^{*}$ & $\mathrm{p}=0.000 *$ & $\mathbf{p}=0.000 *$ & $\mathrm{p}=0.000 *$ \\
\hline
\end{tabular}

The effect of the scores obtained from the secondary traumatic stress scale on the scores obtained from the Covid19 phobia scale was examined with the structural equation model (Figure covariances; It was found as $\chi 237.360$, df 11 $(\mathrm{p}<0.05), \chi 2$ / df 3.396, RMSEA 0.077, GFI 0.974, CFI 0.990, and IFI 0.990 .

It was seen that the indexes of the model were in the desired range [7]. According to the structural equation model established, a statistically significant positive correlation was found between the score obtained from the secondary traumatic stress scale and the score obtained from the Covid19 phobia scale. A 1-unit change that will occur in the total score of the trauma scale causes an increase of 0.68 units in the phobia scale total score $(\beta=0.68 ; \mathrm{p}<0.001)$.

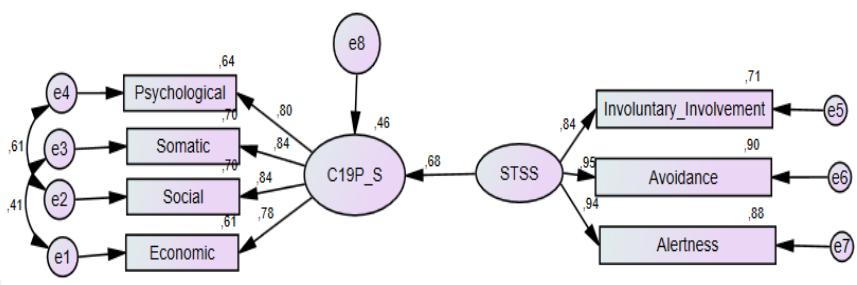

Fig.1. Structural equation model for secondary traumatic stress scale and covid-19 phobia scale.

\section{DISCUSSION}

Secondary traumatic stress is defined as "being in a professional relationship with the person or persons directly experiencing a traumatic event and being indirectly exposed to the trauma" [6] or "the stress resulting from the behavior or desire to help a person who has been traumatized or suffered"[8]. In this study, it was determined that the level of secondary traumatic stress developed in 112 emergency service personnel in the face of COVID 19 pandemic was $39.81 \pm 15.49$. In addition, it was found that STSS scores of female 112 emergency service personnel were higher compared to males and ATT / paramedic personnel had higher scores compared to drivers, undergraduate graduates had higher scores compared to high school graduates, and employees with a history of contact with a Covid-19 positive colleague compared to those without a history of contact
(Table 1, Table 2, p <0.05 for all). In the literature, it has been stated that many factors such as health anxiety, social isolation, stigmatization, and changing working conditions can cause psychological problems such as secondary traumatization for healthcare workers [9]. It is known that acute or chronic stress attacks and psychological problems can cause chronic inflammatory changes in the brain [10]. In this study, it was determined that factors such as gender, education, occupational group and history of contact with a Covid-19 positive colleague are variables that affect the level of secondary traumatic stress. Since the number of the studies on the subject is limited, we suggest that these findings will contribute to the literature. For example, in the study of Arpacioğlu et. al., it has been reported that anxiety, depression, and secondary traumatization scores of healthcare workers who serve in the front lines, during the pandemic process, were significantly higher compared to other healthcare workers or non-medical employees [11]. In addition, in the same study, the factors including being a woman, being in newly beginner in the service, living with parents, having a history of chronic illness and trauma, and increased social media use were reported to increase the level of secondary trauma [11]. Trauma can develop due to many factors.

Many factors can cause trauma. For example, in Thailand, heavy workload of, the lack of protective devices, an ineffective infection control system, surprisingly aggressive attitude towards doctors and other healthcare personnel, vulgar verbal insults and intentional cough against medical staff are cited to be the reasons of trauma experienced by healthcare workers [12]. On the other hand, Li et al., in their study conducted in China, found that the secondary trauma scores of nurses working in the front line during the pandemic process were significantly lower than those who were not in the front line [13]. Although the number of studies limited and psychological impact and secondary trauma levels in healthcare workers are not clear yet, similar causes of trauma have been suggested. Covid-19 pandemic have been transforming into a global trauma due to the fact that the exact reason of the epidemic is not known clearly, the virus cannot be controlled, and all individuals in the world are at potential risk [9].

In this study, it was determined that the scores of C19P$\mathrm{S}$ were higher in female 112 emergency service personnel compared to males; in ATT / paramedics compared to drivers, and in personnel with a history of contact with a Covid-19 positive colleague compared to those without a contact history ( $\mathrm{p}<0.05$ ). On the other hand, it was found that the mean scores of C19P-S was lower in those who had transfer Covid-19 positive patients compared to the others and the level of Covid-19 phobia decreased with increasing age (Table 1, Table 2, $\mathrm{p}<0.05$ ). The main duty of health services is to ensure that individuals continue a healthy life and prevent diseases. Pandemic management and control of infectious diseases are of crucial importance in terms of public health. In the Covid19 pandemic, healthcare workers are at substantially higher risk compared to the rest of the society [14]. For example, in China, where 76.000 cases have been diagnosed, it has been reported that 3000 cases were health personnel [15]. This increased risk as well as the existing workload of the healthcare personnel, leads to an increase in anxiety and stress levels. 
In a study published by Turkish Mental Health Association, it was reported that $50 \%$ of the society afraid of being infected by the virus and $59 \%$ stated that their healthrelated anxiety has increased [16]. In our study, it has been found that, 69\% of the 112 Emergency Service employees were anxious or extremely anxious and the mean C19P-S score was $47.05 \pm 17.01$ (Table 2, Table 3). The level of anxiety regarding a second wave of spread is contemplating, while our country is still struggling in the first wave. In addition, in this study, we examined the relationship between Covid-19 phobia and STSS scores (Table 3; Figure 1) and we determined that a 1-unit change that will occur in the total score of the trauma scale causes an increase of 0.68 units in the Covid-19 phobia scale total score $(\beta=0.68 ; p<0.001)$. This finding show that Covid-19 phobia and secondary traumatic stress levels important variables that affect each other and indicate the need for serious precautions in this regard.

In Italy, $8 \%$ of the Covid-19 cases are health care personnel. In Spain, this rate has been reported to be $14 \%$. These high rates are challenging the health care system and leads to the collapse of the system, in some countries $[17,18]$. In our study, the rate of Covid-19 positivity was found to be $7.5 \%$. During this process, healthcare personnel working in emergency healthcare services constitute a highly risky group. In our study, it was found that $54 \%$ of the 112 emergency service personnel did not live in their homes. This situation is thought to be due to their fear of infecting their families, since they were at greater risk. However, we concern that being away from home may significantly increase the anxiety and stress levels, during this epidemic that affects the whole world and is still uncertain when to end. We think that organizing the work schedules of health care personnel with longer resting times may help reducing the stress burden on them.

\section{CONCLUSIONS}

In this study we investigated the relationship between Covid-19 phobia and secondary traumatic stress level in 112 personnel and we found that as the level of secondary trauma increased, Covid-19 phobia increased significantly. We determined that secondary traumatic stress level is an important variable that increases covid-19 phobia. Among the 112 personnel, the rate of getting a diagnosis of Covid-19 was 7.5\%. Covid-19 phobia was lower in personnel who transferred Covid-19 patients. It was determined that female 112 personnel, those with a history of contact with a Covid19 positive colleague, and those who stated to be extremely anxious about the possibility of a second wave, had a high level of Covid-19 Phobia and Secondary Traumatic Stress levels. We also found that $54.3 \%$ of the 112 personnel have been living in a guest house or a different house, since the onset of the epidemic, to protect their family members. In addition, it was observed that as the age increased, the covid19 phobia decreased and among all 112 employees, drivers had the lowest Covid-19 Phobia and Secondary Traumatic Stress levels.

The impact of the Covid-19 pandemic, which is a global public health problem, on healthcare workers is increasing day by day. It should not be forgotten that health professionals working in risky groups will be psychologically affected much more. In line with these results, it is very important for health managers to create online environments where healthcare personnel, who are at the forefront of combating the pandemic, can cope with stress, and to create a work order in which they can spend safe time with their families. We suggest that, strategies cope should be given through the inservice trainings in order to prevent Covid-19 phobia.

\section{ACKNOWLEDGMENT}

We would like to thank the 112 Emergency Service employees who participated in and completed this questionnaire.

\section{REFERENCES}

[1] Turkish Clinical Microbiology and Infectious Diseases Association (2020). https://www.klimik.org.tr/koronavirus/covid-19-salginindaulkelere-gore-olgu-sayilari/AccespDate: 14.09.2020

[2] Yang, Y., Li, W., Zhang, Q., Zhang, L., Cheung, T., \& Xiang, Y. T. (2020). Mental health services for older adults in China during the COVID-19 outbreak. The Lancet Psychiatry, 7(4), e19.

[3] Seiler, A., Fagundes, C. P., \& Christian, L. M. (2020). The impact of everyday stressors on the immune system and health. In Stress Challenges and Immunity in Space (pp. 71-92). Springer, Cham.

[4] Blanco-Donoso, L. M., Moreno-Jiménez, J., Amutio, A., GallegoAlberto, L., Moreno-Jiménez, B., \& Garrosa, E. (2021). Stressors, job resources, fear of contagion, and secondary traumatic stress among nursing home workers in face of the COVID-19: the case of Spain. Journal of Applied Gerontology, 40(3), 244-256.

[5] Arpaci, I., Karataş, K., \& Baloğlu, M. (2020). The development and initial tests for the psychometric properties of the COVID-19 Phobia Scale (C19P-S). Personality and Individual Differences, 164, 110108.

[6] Yildirim, G., Kidak, L. B., \& Yurdabakan, I. (2018). Secondary Traumatic Stress Scale: An adaptation study/Ikincil Travmatik Stres Olcegi: Bir uyarlama calismasi. Anadolu Psikiyatri Dergisi, 19(1), 4552.

[7] Ozdamar, K. (2016). Scale and test development in education, health and behavioral sciences: Structural equation modeling, Eskişehir, Turkey: Nisan Publisher.

[8] Ratrout, H. F., \& Hamdan-Mansour, A. M. (2020). Secondary traumatic stress among emergency nurses: Prevalence, predictors, and consequences. International journal of nursing practice, 26(1), e12767.

[9] Bozkurt, Y., Zeybek, Z. Așkın, R. (2020). "COVID-19 Pandemıc: Psychological Effects And Therapeutic Interventions", Istanbul Commerce University Journal of Social Sciences, 19(37), 304.

[10] Ramezani, M., Simani, L., Karimialavijeh, E., Rezaei, O., Hajiesmaeili, M., \& Pakdaman, H. (2020). The role of anxiety and cortisol in outcomes of patients with Covid-19. Basic and clinical neuroscience, 11(2), 179.

[11] Arpacioglu, S., Gurler, M., \& Cakiroglu, S. (2021). Secondary traumatization outcomes and associated factors among the health care workers exposed to the COVID-19. The International journal of social psychiatry, 67(1), 84 .

[12] Joob, B., \& Wiwanitkit, V. (2020). Traumatization in medical staff helping with COVID-19 control. Brain, behavior, and immunity, 87, 10.

[13] Li, Z., Ge, J., Yang, M., Feng, J., Qiao, M., Jiang, R., ... \& Yang, C. (2020). Vicarious traumatization in the general public, members, and non-members of medical teams aiding in COVID-19 control. Brain, behavior, and immunity, 88, 916-919.

[14] Turkish Medical Association. Opinion of the Turkish Medical Association Ethics Committee on Outbreaks https://www.ttb.org.tr/makale_goster.php?Guid=4da9a49c-7674-11eab329-aa051764b049. Accessed: 05.09.2020

[15] WHO, "Mental health and psychosocial considerations during COVID$1920 u+20$ https://www.who.int/docs/defaultsource/coronaviruse/mental-health considerations.pdf?sfvrsn=6d3578af_8. Accessed Jully 22, 2020.

[16] Mental Health Association, 2020. https://ruhsagligidernegi.org/etiket/korona-virusu/. Accessed Jully 25, 2020.

[17] Adams, J. G., \& Walls, R. M. (2020). Supporting the health care workforce during the COVID-19 global epidemic. Jama, 323(15), 1439-1440.

[18] Stone, T. E., Kunaviktikul, W., Omura, M., \& Petrini, M. (2020). Facemasks and the Covid 19 pandemic: What advice should health professionals be giving the general public about the wearing of facemasks?. Nursing \& health sciences. 


\section{BIOGRAPHIES}

Serdar Derya, obtained his BSc degree in doctor from Inonu University in 2007 and Medicinae Doctor Department of Traumatology and Emergency Medicine from Inonu University in 2017. He is currently Training and Research Hospital works as physician Malatya, Turkey. He is active in his Traumatology and Emergency Medicine, teaching and research.

Bora Tetik, obtained her BSc degree in doctor from Erciyes University in 2002 and Ass. Prof. Dr. Department of Neurosurgery from Ankara University in 2014. He is currently an Assistant Professor PhD of Inonu University School of Medcine, Department of Neurosurgery, Malatya, Turkey. He ise active in teaching and researching about neurosurgery.

Leman Acun Delen, obtained her BSc degree in doctor from Uludag University in and Medicinae Doctor Department of Anesthesiology and Reanimation from Health Sciences University.She is currently Training and Research Hospital works Malatya, Turkey. She is active in his Anesthesiology and Reanimation, teaching and research. 